\title{
IMPROVED MATHEMATICAL RESULTS AND SIMPLIFIED \\ PEDAGOGICAL APPROACHES FOR GRONWALL'S \\ INEQUALITY FOR FRACTIONAL CALCULUS
}

\author{
Christopher C. Tisdell
}

\begin{abstract}
Gronwall's inequality plays an important role in producing new research and in the learning and teaching of differential and integral equations. The purpose of this work is to advance and simplify the current state of knowledge and pedagogical approaches regarding Gronwall's inequality. In particular: we extend known versions of Gronwall's inequality for fractional calculus; and we provide simpler and more accessible proofs that can be easily transferred to the classroom. Our work is also timely in the sense that it may be considered as a celebration of the upcoming centenary of the publication of Gronwall's original results. Thus, we believe this paper is important from mathematical research, pedagogical and historical viewpoints.
\end{abstract}

Mathematics subject classification (2010): 34A08, 34A40.

Keywords and phrases: Gronwall inequality, fractional calculus, fractional integral inequality, MittagLeffler function, fractional differential equations, pedagogy.

\section{REFERENCES}

[1] R. P. Agarwal and D. O'Regan, An introduction to ordinary differential equations, New York (NY): Springer, 2008.

[2] R. Bellman, The stability of solutions of linear differential equations, Duke Math. J. 10, (1943), 643-647.

[3] R. L. Borelli and C. S. Coleman, Differential equations. A modeling perspective, New York (NY): John Wiley \& Sons Inc, 1998.

[4] F. Brauer And J. A. Nohel, Ordinary differential equations: a first course, Menlo Park (CA): W A Benjamin Inc, 1973.

[5] C. Corduneanu, Principles of differential and integral equations, The Bronx (NY): Chelsea Publishing Company, 1977.

[6] W. R. DERRICK AND S. I. GROSSMAN, Introduction to differential equations with boundary value problems, St Paul (MN): West Publishing Company, 1987.

[7] K. Diethelm AND N. J. Ford, Multi-order fractional differential equations and their numerical solution, Appl. Math. Comput. 154, (2004), 621-540.

[8] R. D. DRIVER, Introduction to ordinary differential equations, New York (NY): Harper \& Row, 1978.

[9] A. ERdélyi, W. Magnus, F. OBerhetTinger AND F. G. Tricomi, Higher transcendental functions, vol. III, based, in part, on notes left by Harry Bateman, New York (NY): McGraw-Hill Book Company, Inc., 1955.

[10] T. H. GRONWALL, Note on the derivative with respect to a parameter of the solutions of a system of differential equations, Ann. of Math. 20, (1919), 292-296.

[11] W. Kelly, A. Peterson, The theory of differential equations. Classical and qualitative, Upper Saddle River (NJ): Pearson Education Inc, 2004.

[12] A. A. Kilbas, H. M. Srivastava and J. J. Trujillo, Theory and applications of fractional differential equations, North-Holland Mathematics Studies, 204, Amsterdam: Elsevier Science B. V., 2006. 
[13] X. Li, Z. LiU AND C. C. TISDell, Existence and exact controllability of fractional evolution inclusions with damping, Math. Meth. Appl. Sci., 40, 12 (2017) 4548-4559. http://dx.doi.org/10.1002/mma.4325

[14] G. MitTAG-LefFleR, Sur la nouvelle fonction $E_{\alpha}(x)$, Comptes Rendus Acad. Sci. Paris. 137, (1903), $554-558$.

[15] G. Mittag-Leffler, Sur la représentation analytique d'une branche uniforme d'une fonction monogéne. (French) cinquiéme note, Acta Math. 29, (1905), 101-181.

[16] O. Platt, Ordinary differential equations, San Francisco (CA): Holden-Day Inc, 1971.

[17] I. Podlubny, Fractional differential equations. An introduction to fractional derivatives, fractional differential equations, to methods of their solution and some of their applications, Mathematics in Science and Engineering, 198, San Diego (CA); Academic Press, Inc.: 1999.

[18] E. O. Roxin, Ordinary differential equations, Belmont (CA): Wadsworth Publishing Company Inc, 1972.

[19] W. T. REID, Properties of solutions of an infinite system of ordinary linear differential equations of the first order with auxiliary boundary condtions, Trans. Amer. Math. Soc. 32, (1930), 294-318.

[20] D. A. SÁnchez, Ordinary differential equations. A brief eclectic tour, Washington (DC): The Mathematical Association of America, 2002.

[21] C. C. TISDELL, On the application of sequential and fixed-point methods to fractional differential equations of arbitrary order, J. Integral Equ. Appl. 24, (2012), 283-319.

[22] C. C. Tis DELL, Solutions to fractional differential equations that extend, Journal of Classical Analysis, 5, (2014), 129-136, http://dx.doi.org/10.7153/jca-05-11.

[23] C. C. TISDell, When do fractional differential equations have solutions that are bounded by the Mittag-Leffler function?, Fractional Calculus and Applied Analysis, 18, (2015), 642-650, http://dx.doi.org/10.1515/fca-2015-0039.

[24] C. C. TISDELL, Basic existence and a priori bound results for solutions to systems of boundary value problems for fractional differential equations, Electronic Journal of Differential Equations, vol. 2016, (2016), no. 84, pp. 1-9.

[25] C. C. Tisdell, Z. LiU And S. MaCNamara, Basic existence and uniqueness results for solutions to systems of nonlinear fractional differential equations, Dynamics of Continuous, Discrete and Impulsive Systems Series A: Mathematical Analysis, 24, (2017), 181-193.

[26] F. Verhulst, Nonlinear differential equations and dynamical systems, Berlin: Springer, 1990.

[27] A. Wiman, Über den Fundamentalsatz in der Theorie der Funktionen $E_{a}(x)$, Acta Math. 29, (1905), 191-201.

[28] E. ZEIDLER, Nonlinear Functional analysis and its applications I. Fixed-point theorems, New York (NY): Springer, 1986. 